\title{
AVALIAÇÃO DO RISCO ERGONÔMICO DE UM OPERADOR AGRÍCOLA EM ATIVIDADE DE TRITURAÇÃO DE RESTOS CULTURAIS
}

\author{
Miguel Chaiben Neto 1*, Jhosefe Bruning ', Silvana Antunes Rodrigues ', Bruna Dalcin Pimenta I, Airton dos Santos Alonço ', Tiago \\ Gonçalves Lopes ${ }^{1}$, Tiago Rodrigo Francetto ${ }^{2}$ \\ ${ }^{1}$ Departamento de Engenharia Rural, Universidade Federal de Santa Maria, 97105-900, Santa Maria, RS, Brasil. \\ ${ }^{2}$ Universidade Federal de Santa Maria - Campus Cachoeira do Sul,96506-322, Cachoeira do Sul, RS, Brasil.
}

*E-mail: miguelchaiben@gmail.com

\section{RESUMO}

O objetivo do trabalho foi avaliar a atividade de um operador, quanto às suas posições no posto de trabalho, bem como a sua exposição aos níveis de ruído em uma operação de trituração de restos culturais da cultura do milho. Além disso, objetivou sugerir as possíveis alterações que corroborassem com a melhoria das condições de trabalho do operador. O estudo foi realizado no município de Santa Maria - RS, onde foi avaliado o posto de trabalho de um operador de um trator agrícola durante a realização de uma atividade de trituração dos restos culturais de uma lavoura de milho, na qual foi utilizado um trator de $75 \mathrm{cv}$ e um triturador de restos culturais de 12 martelos. A operação foi registrada por fotos e vídeos que foram avaliadas pelos métodos OWAS, REBA, RULA e QEC, com o uso do software Ergolândia 7.0. Ademais, o nível de ruído foi medido com o uso de um decibelímetro. De acordo com os dados medidos, foi possível verificar o nível de ruído de $97,1 \mathrm{~dB}$, sendo esse valor superior ao estabelecido pela NR 15. Com a análise dos métodos, foi constatada a necessidade de realizar as intervenções ergonômicas para que a atividade possa ser desempenhada de forma a não ocasionar riscos à saúde do operador.

Palavras-chave: Trator agrícola. RULA. REBA. OWAS. QEC.

\section{Introdução}

A expansão da agricultura foi possível por meio da evolução da mecanização agrícola, sendo os tratores agrícolas as máquinas mais difundidas. Atualmente, há uma preocupação maior dos fabricantes em desenvolver máquinas que possuam um espaço adequado para os operadores que, por sua vez, possam regular o seu posto de trabalho [1].

Segundo Baesso et al. [2], a maioria dos tratores agrícolas em operação no Brasil têm algum problema em relação à segurança e ergonomia do operador. Com a constatação de doenças ocupacionais dos operadores de máquinas agrícolas, temse buscado melhorias nesses postos de trabalho [3].

Para Cunha et al. [4], os tratores advindos das décadas passadas apresentam frequentemente ruídos acima do limite estipulado pela NR 15 [5], que é de 85 decibéis. Esses autores afirmam que mesmo em tratores novos, quando estes não estão equipados com a cabine, os ruídos não são adequados para uma jornada de trabalho de 8 horas.
O ruído gerado pelo funcionamento e deslocamento do conjunto trator/implemento, somado às posturas inadequadas realizadas pelo operador, podem estressar e aumentar a fadiga do operador. Com isso, além de prejudicar a saúde desses trabalhadores, acarretará uma redução de desempenho operacional [6]. Santos et al. [7] recomendam que o trator trabalhe na menor rotação possível, reduzindo, assim, os ruídos e as vibrações causadas pelo deslocamento do conjunto trator/implemento.

Batagin e Patrocínio [8] relatam que os principais problemas relacionados à atividade de trituração de restos culturais consistem na alta incidência do movimento de rotação do pescoço, das costas e do ombro, além da sobrecarga dos punhos do operador durante o deslocamento do trator ao efetuar a atividade.

Diante do exposto, o presente trabalho teve como objetivo a avaliação a atividade de um operador de trator agrícola quanto às suas posições executadas durante a operação de trituração de restos culturais da cultura do milho e a medição dos níveis de ruído sob os quais o mesmo está exposto durante a operação. Ademais, após estas análises, se necessário, empreender sugestões de 
possíveis alterações que corroborem para a melhoria das condições de trabalho do operador.

\section{Metodologia}

O estudo foi realizado no município de Santa Maria - RS, junto ao setor de suinocultura da Universidade Federal de Santa Maria, em uma área utilizada para condução de experimentos científicos, localizada a $29^{\circ} 43^{\prime} 35.0^{\prime \prime} \mathrm{S} 53^{\circ} 43^{\prime} 28.1^{\prime \prime} \mathrm{W}$, onde o solo predominante correspondeu a um Argissolo Vermelho Alumínico Úmbrico.

Foi realizada visita in loco, a fim de obter os dados para as avaliações que ocorreram no mês de maio de 2019, em que foi realizada a análise com o operador do setor durante uma operação de trituração de restos culturais da cultura do milho, sendo esta atividade realizada por meio de um triturador rotativo de 12 martelos acoplado a um trator de $75 \mathrm{cv}$ de potência, fabricado no ano 1986.

Os trajetos percorridos pelo operador eram de, aproximadamente, 50 metros até realizar o retorno e seguir nas linhas adjacentes, operação realizada a uma velocidade média de $5 \mathrm{~km} \mathrm{~h}^{-1}$. Durante a realização dessa atividade, o operador está exposto aos ruídos provocados pela operação, à poeira e às pequenas partículas de material orgânico, oriundas da trituração dos restos culturais do milho.

As análises posturais foram analisadas por meio do acompanhamento de toda a jornada de trabalho, até a finalização da atividade supracitada, em que foram verificadas as principais posturas e o seu tempo de permanência. Para a realização dessa atividade, o operador deve estar atento ao deslocamento do trator e, também, ao funcionamento do triturador de restos culturais.

Assim, para obter uma análise detalhada, foram realizados registros fotográficos de imagens e vídeos durante a realização de toda a operação, uma entrevista com o operador e, além disso, foram aferidas as medidas de ruído (mensurado através de um decibelímetro DEC-460) e os dados obtidos foram avaliados de acordo com a Tabela 1, proposta pela NR 15 [5].
Tabela 1. Limites de tolerância para ruído contínuo ou intermitente

\begin{tabular}{|c|c|c|c|}
\hline $\begin{array}{l}\text { Nível de } \\
\text { ruído dB }\end{array}$ & $\begin{array}{l}\text { Máxima exposição } \\
\text { diária permissível }\end{array}$ & $\begin{array}{l}\text { Nível de } \\
\text { ruído dB }\end{array}$ & $\begin{array}{l}\text { Máxima exposição } \\
\text { diária permissível }\end{array}$ \\
\hline 85 & 8 horas & 98 & 1 hora e $15 \mathrm{~min}$. \\
\hline 86 & 7 horas & 100 & 1 hora \\
\hline 87 & 6 horas & 102 & 45 minutos \\
\hline 88 & 5 horas & 104 & 35 minutos \\
\hline 89 & 4 horas e $30 \mathrm{~min}$. & 105 & 30 minutos \\
\hline 90 & 4 horas & 106 & 25 minutos \\
\hline 91 & 3 horas e $30 \mathrm{~min}$. & 108 & 20 minutos \\
\hline 92 & 3 horas & 110 & 15 minutos \\
\hline 93 & 2 horas e $40 \mathrm{~min}$. & 112 & 10 minutos \\
\hline 94 & 2 horas e $15 \mathrm{~min}$. & 114 & 8 minutos \\
\hline 95 & 2 horas & 115 & 7 minutos \\
\hline 96 & 1 hora e $45 \mathrm{~min}$. & & \\
\hline
\end{tabular}

Fonte: Adaptado da NR 15 do Ministério do Trabalho e Emprego - Atividades e operações Insalubres, 1978.

A análise postural foi avaliada com o auxílio de ferramentas ergonômicas que compreendem a observação da atividade em seu local de trabalho, a fim de verificar quais são as reais condições ergonômicas às quais o operador está exposto. Para tanto, foram utilizados os seguintes métodos para as análises: OWAS (Ovako Working posture analysing system), RULA (Rapid Upper Limb Assessment), REBA (Rapid Entire Boby Assessment) e QEC (Quick Exposure e Check for work related musculoskeletal risck), através da utilização do software Ergolândia 7.02019.

O método OWAS analisa as posturas das costas, braços, pernas e do esforço do trabalhador, bem como do tempo em que o trabalhador permanece em cada postura, sendo avaliados os níveis de intervenção em função dos dígitos dos fatores avaliados de acordo com a Tabela 2.

Tabela 2. Descrição das categorias de ação do método OWAS

\begin{tabular}{cc} 
Categorias & Nível de intervenção \\
\hline 1 & Não são necessárias medidas corretivas; \\
2 & São necessárias correções em um futuro próximo \\
3 & São necessárias correções tão logo quanto possível \\
4 & São necessárias correções imediatas \\
\hline
\end{tabular}

Fonte: Adaptado de Ergolândia 7.0 (2019). 
O método RULA tem como finalidade avaliar a exposição dos trabalhadores aos fatores de risco que ocasionam transtornos nos membros superiores do corpo. Assim, cada fator recebe uma determinada pontuação que expressa o nível de intervenção necessária em função da atividade desempenhada pelo trabalhador, conforme mostra a Tabela 3.

Tabela 3. Descrição da pontuação para cada nível de intervenção do método RULA.

\begin{tabular}{ccc} 
Nível & Pontuação & Nível de intervenção \\
\hline 1 & 1 ou 2 & Postura aceitável \\
2 & 3 ou 4 & $\begin{array}{c}\text { Deve-se realizar uma observação. Podem ser necessárias } \\
\text { mudaças }\end{array}$ \\
3 & 5 ou 6 & $\begin{array}{c}\text { Deve-se realizar uma investigação. Devem ser } \\
\text { introduzidas mudanças }\end{array}$ \\
4 & 7 & Podem ser introduzidas mudanças imediatamente.
\end{tabular}

Fonte: Adaptado de Ergolândia 7.0 (2019).

O método REBA foi desenvolvido para avaliar a exposição dos trabalhadores aos fatores de risco que venham ocasionar danos aos membros superiores e inferiores do corpo, em função dos movimentos repetitivos. A aplicação deste método resulta em pontuação que corresponde a determinados significados e, consequentemente, se enquadra em um dos cinco níveis de intervenção, conforme mostra a Tabela 4.

Tabela 4. Pontuação para determinar o nível de intervenção ergonômica necessária pelo método REBA

\begin{tabular}{ccc}
\hline Pontuação & Significado & Nível de intervenção \\
\hline 1 & Risco insignificante & Não é necessária \\
2 ou 3 & Risco baixo & Pode ser necessária \\
4 a 7 & Risco médio & Necessária \\
8 a 10 & Risco alto & Necessária o quanto antes \\
11 & Risco muito alto & Necessária imediatamente \\
\hline Fonte $:$ Adaptado de Ergolândia $7.0(2019)$ &
\end{tabular}

O método QEC é um método composto por um formulário de avaliação com 15 questões, em que uma parte é preenchida por meio das observações do avaliador e outra é respondida pelo trabalhador, no que concerne às posturas e os movimentos realizados por coluna e membros superiores, assim como outros fatores de risco, (quantidade de peso manuseado; tempo de realização da tarefa; força manual; demanda visual da atividade; presença de vibração e direção de veículos; ritmo de trabalho; e estresse).Este formulário de pontuação possibilita a quantificação parcial (por região corporal) e total do risco. Esta pontuação resulta da combinação entre as respostas do avaliador e do trabalhador. Dessa forma, as faixas de pontuação podem ser classificadas em quatro categorias de exposição ao risco, conforme mostra a Tabela 5 .
Tabela 5. Interpretação da pontuação dos níveis de exposição dos trabalhadores pelo método de QEC

\begin{tabular}{ccccc}
\multirow{2}{*}{ Região corporal } & \multicolumn{4}{c}{ Nível de exposição } \\
\cline { 2 - 5 } & Baixo & Moderado & Alto & Muito alto \\
\hline Coluna estática & $8-14$ & $16-22$ & $24-28$ & $30-40$ \\
Coluna Dinâmica & $10-20$ & $22-30$ & $32-40$ & $42-56$ \\
Ombro / braço & $10-20$ & $22-30$ & $32-40$ & $42-56$ \\
Punho / mão & $10-20$ & $22-30$ & $32-40$ & $42-56$ \\
Pescoço & $4-6$ & $8-10$ & $12-14$ & $16-18$ \\
Direção & 1 & 4 & 9 & - \\
Vibração & 1 & 4 & 9 & - \\
Ritmo de trabalho & 1 & 4 & 9 & 16 \\
\hline Estresse & 1 & 4 & 9 &
\end{tabular}

\section{Resultados e discussões}

O estudo compreendeu a realização da análise e interpretação do posto de trabalho de um tratorista durante a operação de trituração de restos culturais, em que o trabalhador muda constantemente de postura, uma vez que o triturador é acoplado na parte traseira do trator para a execução do trabalho, obrigando, assim, o operador a manter-se atento, tanto para o caminho que será percorrido (para frente) como no funcionamento do equipamento (na parte traseira).

Durante a execução da atividade, foi verificada a predominância de duas posições principais, sendo a primeira delas correspondente à posição em que o operador permanece sentado no banco de frente para a direção do trator e, nesta posição, o operador encontra-se com a coluna apoiada no banco, uma das mãos firme no volante e a outra mão sob os comandos hidráulicos para levantar e baixar o implemento. Já na segunda posição, o operador apresenta uma rotação do tronco em função da necessidade de observar o funcionamento do implemento e evitar os possíveis danos que possa sofrer durante a execução da atividade. Esses resultados estão de acordo com estudo de [10], desenvolvido no setor florestal em atividade de subsolagem e [11] em operação de preparo do solo, em que ambos evidenciaram as mesmas posições durante a realização das atividades.

Tabela 6. Métodos de avaliação ergonômica aplicados a atividades do operador agrícola na execução da trituração de restos culturais

\begin{tabular}{ccc} 
Método & Pontuação & Intervenção \\
\hline OWAS & 2 & São necessárias correções em um futuro próximo \\
RULA & 7 & Podem ser introduzidas mudanças imediatamente \\
REBA & 7 & Necessária \\
\hline
\end{tabular}


Para os três métodos utilizados, foi detectada a necessidade de alguma intervenção, seja em um futuro próximo ou mesmo de maneira imediata. Estes resultados se justificam em função dos movimentos de rotação do tronco, pescoço e movimentação dos membros superiores, que o operador necessita realizar durante a atividade de trituração dos restos culturais.

No que concerne à utilização do método QEC, os resultados encontrados durante a avaliação são apresentados na Tabela 7. Nela, o método discrimina os níveis de exposição de cada membro do corpo, envolvidos durante a atividade.

Tabela 7. Nível de exposição por região corporal para o método QEC.

\begin{tabular}{ccc}
\hline Região corporal & \multicolumn{2}{c}{ Nível de exposição } \\
\hline Coluna estática & 20 & Moderado \\
Coluna Dinâmica & 20 & Baixo \\
Ombro / braço & 24 & Moderado \\
Punho / mão & 30 & Moderado \\
Pescoço & 10 & Moderado \\
Direção & 4 & Moderado \\
Vibração & 4 & Moderado \\
Ritmo de trabalho & 4 & Moderado \\
Estresse & 9 & Alto \\
\hline
\end{tabular}

Os resultados demonstraram que a maioria dos membros estão em nível de exposição moderado, com valores no seu limite para atingir níveis mais elevados de exposição. Isso corrobora com estudo de Comper e Padula [9], sobre uma atividade industrial na qual o trabalhador permanece na posição sentada, com rotações do tronco, membros superiores e movimentos repetitivos, sendo nesta atividade considerado como moderado o nível de exposição para o ombro/braço e o pescoço, já para punho/mão e a coluna lombar considerado alto, sendo estes superiores aos obtidos no presente estudo devido a intensidade de repetição dos movimentos.

Segundo Comper e Padula [9], a utilização deste método favorece a identificação das regiões corporais mais expostas ao risco e os fatores de risco e, por isso, é indicado para melhorias ergonômicas. $\mathrm{O}$ fator de maior preocupação está relacionado à questão de estresse em função do ruído, sendo este fator elencado pelo operador como o de maior incômodo em relação às demais regiões corporais durante a realização da tarefa.

A utilização do método QEC pode ser uma boa opção para analisar este tipo de situação, pois avalia a exposição biomecânica por região corporal. Permite, assim, analisar a exposição ao risco por meio da combinação dos fatores de risco biomecânicos, identificados pelo observador e pelas respostas do trabalhador.

Durante a execução dessa atividade, ocorre a predominância da posição do operador sentado, com exceção de alguma necessidade de manutenção. Segundo os autores De Guimarães et al. [12], os distúrbios lombares não são causados apenas por cargas que atuam sobre a coluna vertebral, mas principalmente pela permanência em postura estática. Não obstante, quando o trabalhador estiver sentado com uma postura inadequada, esta posição pode causar danos à saúde do trabalhador até $40 \%$ maiores quando comparados com a posição em pé, pelo fato de esta posição favorecer a compressão dos discos intervertebrais. Além disso, segundo Mokarami et al. [13], o uso prolongado de tratores agrícolas aumenta a probabilidade de distúrbios musculoesqueléticos, além do alto nível de risco de posturas inadequadas.

Em relação aos ruídos durante a realização da atividade, foram encontrados resultados que mostraram valores médios de 97,1 dB, que é semelhante ao encontrado por Baesso et al. [1] para o mesmo tipo de trator. Além disso, os mesmos autores relatam que diversos tratores apresentaram níveis de ruído superiores aos estipulados pela norma NR 15 [5] para jornadas de trabalho de oito horas diárias. Sendo assim, os operadores e auxiliares estariam sujeitos aos riscos de hipoacusia, quando trabalham sem proteção auricular. De acordo com Baesso et al. [2], a maioria dos tratores agrícolas sem cabine apresentam um nível de ruído superior a 85 $\mathrm{dB}$, sendo assim, obrigatório o uso de protetores auriculares ou a redução da jornada de trabalho diária.

De acordo com a NR 15 [5], os resultados encontrados evidenciam que a máxima exposição diária permissível seria de, aproximadamente, 1 hora e 30 minutos. No entanto, quando a atividade é realizada com o uso de protetores auriculares, a mesma não pode ser considerada como insalubre, pois o uso do protetor reduz em 12 dB o nível de ruído.

Para assegurar a saúde auditiva do trabalhador, Braga et al. [14] relatam que o valor de $140 \mathrm{~dB}$ corresponde à exposição máxima que nossos tímpanos podem suportar, sob a pena de rompimento. A partir de $90 \mathrm{~dB}$, ocorre o desconforto acústico, com danos ao organismo humano. Ainda, segundo os mesmos autores, o excesso de ruído tem influência no humor, na concentração, perda de apetite e causa fadiga auditiva.

Diante dos resultados obtidos, as medidas que podem ser adotadas seriam: a instalação de espelhos retrovisores com a finalidade de verificar a parte traseira, ou, a instalação de uma câmera traseira na máquina, interligada por meio de uma tela, para o operador visualizar o implemento no decorrer da atividade em 
execução, bem como o ajuste do assento do operador para evitar as posturas inadequadas.

Outra recomendação que poderia ser inserida para reduzir os desconfortos causados pela jornada de trabalho, na posição sentada, principalmente das pernas, seria a introdução de intervalos durante a execução da operação, para a realização de caminhadas e/ou alongamentos.

\section{Conclusões}

A operação de trituração de restos culturais por meio dos métodos de análise ergonômica mostrou a necessidade de intervenção em curto prazo.

A utilização de mais de um método de avaliação ergonômico traz ao profissional da área de ergonomia algumas informações complementares para evidenciar os mínimos detalhes das atividades, às quais estão sendo analisadas.

Simples adequações podem ser inseridas para reduzir os problemas posturais e a utilização obrigatória de protetores auriculares é necessária.

\section{Agradecimentos}

Ao Conselho Nacional de Desenvolvimento Científico e Tecnológico (CNPq) pela bolsa de estudos concedida.

\section{ERGONOMIC RISK ASSESSMENT OF AN AGRICULTURAL MACHINE OPERATOR IN THE GRINDING OF CROP RESIDUES}

ABSTRACT: The objective of this study was to evaluate the activity of an agricultural machine operator regarding his position in the workplace and his exposure to noise levels in an operation to grind crop residues of corn, besides suggesting possible changes to improve the operator's working conditions. The study was carried out in the municipality of Santa Maria -RS, Brazil. The work station of an agricultural tractor operator was evaluated during the grinding activity of corn crop residues, for which a 75hp tractor and a flail mower of 12 hammers were used. The operation was recorded in photos and videos, which were evaluated according to the methods OWAS, REBA, RULA and QEC, by using software Ergolândia 7.0. In addition, noise levels were measured using a decibel meter. The measured data showed a noise level of $97.1 \mathrm{~dB}$, which is higher than the value established by the NR 15. Through the analysis of the methods it was verified the need to perform ergonomic interventions so that the activity may be carried out in a way not to cause health risks to the operator.

Keywords: Agricultural tractor. RULA. REBA. OWAS. QEC.

\section{REFERÊNCIAS}

[1] BAESSO, M. M.; MODOLO, A. J.; BAESSO, R. C. E.; FISCHER, C. Níveis de ruído emitidos por tratores agrícolas. Revista Brasileira de Engenharia de Biossistemas, São Paulo, v. 11, n. 3, p. 229-238, 2017. DOI: http://dx.doi.org/10.18011/bioeng2017v11n3p229-238

[2] BAESSO, M. M.; GAZZOLA, M.; BERNARDES, S.; BRANDELERO, E.; MODOLO, A. Avaliação do nível de ruído, itens de segurança e ergonomia em tratores agrícolas. Revista Brasileira de Engenharia de Biossistemas, São Paulo, v. 9 , n. 4, p. 368-380, 2015. DOI: http://dx.doi.org/10.18011/bioeng2015v9n4p368380

[3] SILVA, P. R.A. Precauções de segurança nas operações com equipamentos agrícolas. In: MONTEIRO, L. A. Prevenção de acidentes com tratores agrícolas. Botucatu: Diagrama, 2010. cap. 2, p. 33-50

[4] DA CUNHA, J. P. A.R.; VIANA DUARTE, M. A.; DE SOUZA, C. M. A. Vibração e ruído emitidos por dois tratores agrícolas. Idesia: Revista de Agricultura de Zonas Áridas,Arica, v. 30, n. 1, p. 25-34, 2012. DOI:http://dx.doi.org/10.4067/S0718-34292012000100004

[5] NR15 - Norma Regulamentadora: Atividades e condições insalubres. ABNTAssociação Brasileira de Normas Técnicas. Disponível em: 〈http://www.guiatrabalhista.com.br/legislacao/nr/nr15.htm>

[6] DE SOUZA, A. P.; DUTRA, R. B. C.; MINETTE, L. J.; DA CUNHA MARZANO, F. L.; SCHETTINO, S. Metas de produção para trabalhadores de corte florestal. Revista Árvore, Viçosa, v. 39, n. 4, p. 713-722, 2015. DOI: http://dx.doi.org/10.1590/0100-67622015000400014

[7] SANTOS, D. W. F. N,; FORASTIERE, P. R.; JUNIOR, M. R. F.; VALENTE, D. S. M.; FERNANDES, H. C. Parâmetros ergonômicos e operacionais de um conjunto trator-escarificador em função da rotação do motor e pressão interna dos pneus. Revista de Ciências Agrárias - AmazonianJournal of Agriculturaland Environmental Sciences, Belém, v. 59, n. 4, p. 401-408, 2016. DOI: http://dx.doi.org/10.4322/rca.2574

[8] BATAGIN, F. G. R.; PATROCÍNIO, A.B. Analise ergonômica do posto de trabalho pelo método Ergonimic Workplace Analysis- EWA. REGENT, Piracicaba, v. 2, n. 1, 2017.

[9] COMPER, M. L C.; PADULA, R. S. Avaliação do risco ergonômico em trabalhadores da indústria têxtil por dois instrumentos: quick exposure check e job factors questionnaire. Fisioterapia e Pesquisa, São Paulo, v. 20, n. 3, p. 215-221, 2013.DOI: http://dx.doi.org/10.1590/S1809-29502013000300004.

[10] DE AZEVEDO, A. M. Avaliação Ergonômica do Ambiente de Trabalho na atividade do operador agrícola. COGNITIO/PÓS-GRADUAÇÃO UNILINS, Lins, v. 1, n. 1, 2014.

[11] POTT, L. P.; DEPOI, J.; dos SANTOS ALONÇO, A.; POSSEBOM, G.; LOPES, T. G.; BECKER, R. S.; CARPES, D.P.; DONATO, G. Análise postural de operador agrícola na atividade de preparo do solo em áreas de várzea. TecnoLógica, Santa Crus do Sul, v. 23, n. 1, p. 22-27, 2019. DOI: http://dx.doi.org/10.17058/tecnolog.v23i1.12377

[12] DE GUIMARÃES, B. M.; MARTINS, L. B.; de AZEVEDO, L. S.; do AMPARO ANDRADE, M. Análise da carga de trabalho de analistas de sistemas e 


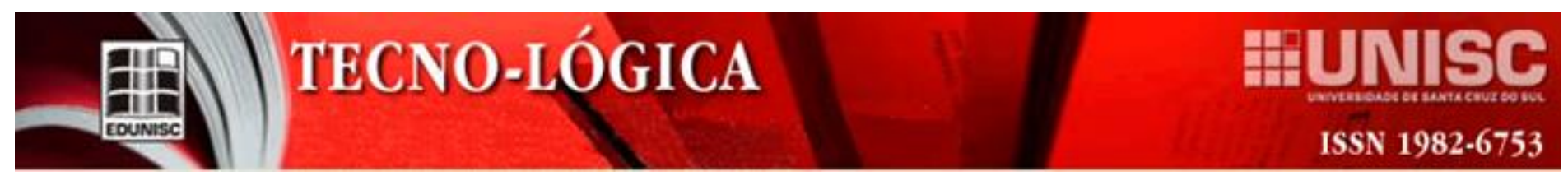

dos distúrbios osteomusculares. Fisioterapia em Movimento, Curitiba, v. 24, n. 1 , p. 115-124, 2011. DOI: http://dx.doi.org/10.1590/S0103-51502011000100013.

[13] MOKARAMI, H.; KALTEH, H. O.; TAJPOOR, A. Analysis of body postures for preventing musculoskeletal disorders among tractor drivers in Iran. Journal of Health Sciences \& Surveillance System, Shiraz, v. 5, n. 3, p. 100-106, 2018.

[14] BRAGA, B.; HESPANHOL, I.; CONEJO, J. G. L.; MIERZWA, J. C.; BARROS, M.T. L.; SPENCER, M.; PORTO, M.; NUCCI, N.; JULIANO, N.; EIGER, S. Introdução à Engenharia Ambiental. 2. Ed. São Paulo: Prentice Hall, 2005. 